\title{
El precio del progreso: de la «virtualización del mundo» al «zombismo hiperindividualista»
}

\author{
The price of progress: from "virtualization of the world» \\ to «byper-individualistic zombism»
}

BORJA GARCÍA FERRER

UNIVERSIDAD DE GRANADA

Artículo recibido: 18 abril 2015

Solicitud de revisión: 28 mayo 2015

Artículo aceptado: 1 diciembre 2015

Resumen

El objetivo del trabajo es mostrar las funestas repercusiones del bombardeo de informaciones que todos padecemos en nuestro incipiente mundo virtual. Si bien es cierto que trae consigo numerosas ventajas, desde que el capitalismo basa su fuerza y expansión en las nuevas tecnologías de la comunicación, la proliferación acelerada de estímulos concomitante también conlleva una crisis de transmisión de consecuencias fatídicas, en la medida que arruina la estructura normativa firme y estable que vertebraba nuestras vidas en la prehistoria digital. De aquí se sigue, por razón de semejante vacío axiológico, una hiperinversión de lo privado y una desmovilización del espacio público, convertido en un inquietante desierto virtual donde zombis hiperindividualistas interactúan en el simple sentido de la palabra, al ritmo que marcan los nuevos expertos en las artes de la infoesfera.

Palabras clave: mundo virtual, crisis de transmisión, organización del vacío, narcisismo colectivo

\begin{abstract}
The aim of this work is to show the disastrous effects of the bombardment of information which all of us experience in our emerging virtual world. It is true that capitalism brings a great number of advantages; however, since it bases its strength and expansion on the new communication technologies, the accompanying accelerated proliferation of stimuli also involves a crisis of transmission of fatal consequences, in so far as it ruins the solid and stable regulatory structure that provide the backbone of our lives in digital prehistory. It follows, because of such axiological vacuum, a hyperinversion of the private sphere and a demobilization of public space, turned into a disturbing virtual desert where hyperindividualistic zombies interact in the simple sense of the word, at the pace set by the new experts on the arts of infosphere.
\end{abstract}

Keywords: Virtual World, Transmission Crisis, Organization of Emptiness, Collective Narcissism 


\section{UN MUNDO VIRTUAL}

Para poner de manifiesto el declive que sufre, a nuestro juicio, el cuerpo social en su conjunto, es de recibo comenzar caracterizando el horizonte de sentido donde tienen lugar y se desarrollan los agenciamientos e hibridaciones que lo constituyen, esto es, el sistema global de comunicación, también conocido como «sociedad de la información»o «infoesfera». Y es que, según las consideraciones más elementales de Ortega y Gasset, el problema de las relaciones humanas se cifra en el problema de la vida, esto es, del hombre en el mundo (Ortega y Gasset, 2005). Contra la filosofía del sujeto, el ser humano no es una conciencia trascendental, sino un ser histórico concreto arrojado en unas circunstancias determinadas. Ahora bien, como enseña Ortega, las circunstancias no son meras cosas o la suma de ellas; bien pensadas, son una suerte de escenario, porque la vida es drama o tragedia, y vivir es tratar con nuestras circunstancias, actuar en ellas. De tal suerte que el horizonte donde nos encontramos inmersos nos constituye, designando nuestro destino radical y concreto.

Aunque la información designa, en cuanto fuente de poder y significado, un denominador común de todos los tiempos, el advenimiento de las nuevas tecnologías de la telecomunicación y su difusión vertiginosa por la totalidad del orbe nos arroja inexorablemente a la llamada «era de la información», en lo que constituye - a tenor del papel fundamental que juegan en el nuevo orden mundial, pero también de sus inestimables repercusiones en la existencia cotidiana- la tercera gran revolución de la historia, tras la escritura y la imprenta. Efectivamente, el paradigma tecnológico engendrado por la revolución microelectrónica de los años 40 trae consigo una transformación ontológica sin precedentes de las relaciones espacio-temporales, una "convulsión estructural» de las condiciones de posibilidad y desarrollo de la distancia según la cual todo topos puede compartir el mismo tiempo cuantitativo, a pesar de que no exista, al menos en apariencia, articulación espacio-temporal entre ellos. En contraste al viejo mundo, donde la existencia de fenómenos distantes respondía a un acto de fe (Wittgenstein, 1988), las telecomunicaciones implican una suerte de desterritorialización que conserva, paradójicamente, las respectivas coordenadas locales de los comunicantes, permitiendo asistir virtualmente a fenómenos antaño inaccesibles en tiempo real, sin dilación ni efecto diferido.

En el pasado, las nociones de espacio y tiempo habían sido ya modificadas, es cierto, mediante tecnologías más rudimentarias en el ámbito de los medios de locomoción. Sin embargo, el cambio ontológico experimentado 
a la altura del presente sería impensable sin el concurso de la portabilidad. Como advierte Enrique Lynch, la portabilidad suele asimilarse al proceso de «miniaturización», esa tendencia universal de la tecnología digital a reducir drásticamente el espacio operativo de los dispositivos electrónicos para satisfacer las aspiraciones de la masa a concentrar en ellos el mayor número posible de complementos: agenda, radio, cámara, álbum de imágenes, reproductor de música, GPs... ${ }^{1}$ Ahora bien, la tecnología portátil no sólo estriba en las necesidades de sus usuarios, sino que es la conditio sine qua non del nuevo espacio virtual de las telecomunicaciones.Y es que, más allá de las comunicaciones de larga distancia en la telefonía clásica, donde la conexión era sostenida por líneas físicas y las llamadas estaban supeditadas geográficamente, la tecnología inalámbrica consigue la hazaña de vincular diversos puntos móviles, superando las limitaciones derivadas del sentido espacial tradicional. El teléfono celular radicaliza, en este sentido, la dimensión virtual de la infoesfera, en tanto que graba dichas posiciones comunicativas en un espacio creado por ella misma, de tal suerte que la técnica logra apoderarse del espacio liberado por la telecomunicación.

Como consecuencia, tenemos la implosión definitiva del espacio-tiempo clásico absoluto en beneficio de la «virtual-realidad» o, si se prefiere, «real-virtualidad», ${ }^{2}$ ese lugar «existente» allende lo geográfico, extravagante e inverosímil, donde cualquier parte se trueca en «ninguna parte». Se trata del «Tercer entorno», caracterizado como un espacio informacional -funciona mediante representaciones electrónicas de bits-, representacional - los sujetos y los objetos no son cuerpos, sino representaciones tecnológicamente construidas-, comprimido - los objetos ocupan una extensión mínima-, asentado en el aire - basado en el espacio informacional generado por las NTIC-, con movilidad electrónica -intervenimos en ellos mediante flujos electrónicos-, bisensorial -audiovisual, aun siendo multimedia-, digital -sus entidades están digitalizadas y son percibidas mediante artefactos digitales-, distal - permite interactuar a gran distancia- y reticu-

1 Se trata de la variante digital de una costumbre que hunde sus raíces en la condición humana. Como ilustran Lord Byron, Lord Blessington y otros viajeros románticos ingleses, acompañados por todo tipo de enseres personales en sus viajes por el Mediterráneo, los hombres siempre han procurado llevar consigo todas sus pertenencias, al hilo del ancestral nomadismo de nuestra especie (Lynch, 2010: 89-90).

2 Desde esta óptica, las nuevas tecnologías de la comunicación consuman en las praxis, averiguaciones teóricas cruciales para el advenimiento de la nueva realidad virtual, como son la «relatividad especial» de Einstein, la física cuántica, la teoría matemática de campos aplicada a la física o las investigaciones en torno al Bosón de Higgs. 
lar - su topología no se basa en recintos, sino en una red proteica trazada por enlaces móviles interconectados- (Echeverría, 2000: 77-78). ${ }^{3}$

Pero si bien es mucho más artificial que los entornos urbanos y metropolitanos, no por ello deja de ser un espacio real, como revela la influencia de las redes telemáticas que todos experimentamos cotidianamente:

En un sentido estricto, tiene poca afinidad con lo falso, lo ilusorio o lo imaginario; lo virtual no es, en modo alguno, lo opuesto a lo real, sino una forma de ser fecunda y potente que favorece los procesos de creación, abre horizontes, cava pozos llenos de sentido bajo la superficialidad de la presencia física inmediata (Lévy, 1999: 14).

Se trata, así pues, de una especie de Ars Inveniendi, en la medida que modifica y amplía la misma noción de realidad. Ahora bien, la virtualidad no consiste en una especie de género supremo que constituye todo lo que es; lejos de designar un principio trascendental, tiene consecuencias perfectamente actualizadas $y$, por tanto, puede ser controlada arbitrariamente por todo tipo de tensiones y presiones opacas para los usuarios, pero con la autonomía suficiente para determinar su comportamiento. De hecho, los artefactos tecnológicos que vertebran el nuevo «espacio virtual» integran paulatinamente todas nuestras referencias vitales en sus redes de comunicación:

Desde los listines de teléfono hasta los posibles itinerarios de un viaje, las reservas de los pasajes o de las entradas de cine, la información puntual de todos los hechos, la intimidad de los individuos en los blogs, las obras de arte y los libros, los archivos, los trámites burocráticos, los álbumes de familia, el trapicheo amoroso en los chats, las transacciones bursátiles, las enciclopedias médicas que permiten autodiagnosticarse y automedicarse, y las apuestas de juego, etc. El mundo entero se reconstruye en este nuevo espacio-tiempo virtual (Lynch, 2010:95).

Cabe preguntarse, entonces, si por fin asistimos al lugar del encuentro y la comunicación sin fronteras con el que siempre ha soñado la humanidad o si será, simplemente, el nuevo espacio del poder «pastoral», esa forma de dominio ejercido mediante procesos anónimos de dirección que, por oposición al esquema represivo freudiano, gobiernan los cuerpos y las mentes manipulando y promocionando nuestra conducta (Foucault, 2012).

En cualquier caso, el mundo ya no es el mismo desde la implantación de la red mundial de las telecomunicaciones portátiles. Es más, como intentaremos demostrar, las nuevas tecnologías de la información no solo trans-

3 Javier Echeverría ha estudiado con detalle las propiedades estructurales del «Tercer entorno», en contraste a los espacios naturales y urbanos (Echeverría, 1999). 
forman el mundo en sentido exógeno sino que también cambian a sus propios usuarios, más allá de los instrumentos tradicionales. En este sentido, la «realidad virtual» contemporánea evoca la figura de Don Quijote pues, según cuenta Cervantes, el caballero andante se sumerge tanto en los libros de caballería que termina superponiendo sus símbolos característicos a los lugares que recorre, alterando su percepción del mundo y el sentido de sus acciones hasta el prurito de vivir un mundo virtual:

La tecnología ha sustituido a Rocinante por el mando a distancia, pero la vida cotidiana ha seguido impregnándose de virtualidad. La propaganda y el espectáculo televisivo tienen efectos reales sobre las personas, pese a ser construcciones artificiales. Parecida influencia ejercieron los libros de caballerías sobre el hidalgo de La Mancha (Echeverría, 2000: 23).

La cuestión es, ¿cuáles son las consecuencias de la nueva «realidad virtual» para el ser humano de carne y hueso?

\section{LA CRISIS DE TRANSMISIÓN EN PERSPECTIVA HISTÓRICA}

A decir verdad, debemos proceder con extrema prudencia a la hora de evaluar las repercusiones del progreso tecnológico en nuestras vidas, dado que el giro que supone la emergencia de la virtualidad en el espacio-tiempo tradicional es un fenómeno incipiente y, como es sabido, la filosofía siempre llega demasiado tarde. Lo primero que debemos considerar es que, contra la opinión generalizada de que la nueva técnica conlleva cierta «deshumanización», no existen tecnologías inhumanas sino usos inhumanos de la tecnología. De hecho, el espacio virtual de las comunicaciones globales repercute positivamente en nuestra experiencia del espacio y del tiempo, en la medida que nos permite participar en fenómenos muy lejanos y, por consiguiente, la vida cotidiana se torna mucho más rica en incidencias:

\footnotetext{
No solo imagino que algo sucede en este mismo momento en otra parte, sino que ahora lo sé,y, además, puedo comprobarlo llamando por teléfono. El mismo efecto, como de una experiencia real ampliada, lo produce la televisión. Con la televisión no solo oigo lo que sucede muy lejos de mí sino que además lo veo (Lynch, 2010: 80).
}

Asimismo, las nuevas tecnologías de la comunicación encierran potencias positivas que escapan al ámbito de las meras «incidencias». Cómo abordarlas rebasaría los límites del presente trabajo, sirvan como botón de muestra las condiciones privilegiadas que ofrecen de cara a la emancipación, en un sentido ético-político (Hardt y Negri, 2004). Pero del mismo 
modo que reconocemos sus virtudes, tampoco comulgamos con las apologías posmodernas que celebran acríticamente las bondades sociológicas de la «hipervirtualidad», pues el progreso tecnológico encierra un carácter ambiguo, en virtud del cual es, por así decirlo, pharmakon, veneno y remedio al mismo tiempo. En lo que concierne a las telecomunicaciones, por ejemplo, la extraordinaria ampliación del nivel de experiencia conlleva un espacio-tiempo de seguridad precaria, como revelan los virus, el tráfico ilegal de datos privados y otros rostros de la «hiperfobia» contemporánea, esa sensación velada de catástrofe implementada espuriamente por los mass media. ${ }^{4}$

En cualquier caso, el advenimiento de una nueva época reclama, frente a los profetas de la ruptura absoluta, un retorno prudente al anterior estado de cosas en aras de comprender las transformaciones que acarrea en la existencia: lo nuevo demanda la genealogía. Desde un punto de vista histórico, el nuevo devenir virtual se funda, para nosotros, en la lógica artística que coliga las diversas vanguardias artísticas allende su singularidad irreductible, ese código de la actualidad que convierte lo inédito en el imperativo categórico de la libertad artística a costa de todos los cánones establecidos:

El cambio se convierte en revolución, brusca ruptura en la trama del tiempo, discontinuidad entre un antes y un después, afirmación de un orden radicalmente distinto. [...] El modernismo prohíbe el estancamiento, obliga a la invención perpetua, a la huida hacia delante (Lipovetsky, 1990: 81).

Pues bien, en la medida que participa del mismo culto por la novedad y el cambio que el modernismo, el trepidante desarrollo de la infoesfera designa una rebelión contra sí misma, un proceso de negación sin límites cuya obsolescencia fulgurante desprecia todo lo que genera en cuanto viene registrado, donde todo lo nuevo se torna repentinamente obsoleto. ${ }^{5}$ No obstante, la contradicción dinámica del modernismo encuentra en el universo cultural de la comunicación una prolongación no menos contra-

4 La mejor estrategia de pensamiento para entender el mundo de la virtualidad se cifra, para nosotros, en una tercera vía ideológica y ontológica entre los «integrados» que asimilan lo virtual a una especie de paraíso terrenal, como Flusser y Weibel, y los «apocalípticos» mediáticos, como Virilio (Oliveira, 2010: 233-234). Por lo demás, nos remitimos al clásico de Humberto Eco, Apocalípticos e integrados -1965-, para profundizar en este punto; resultan especialmente interesantes sus reflexiones añadidas en la edición de 1995 (Eco, 1995).

5 Cada vez más informaciones, cada vez más deprisa, los lugares han experimentado el mismo abandono que los acontecimientos: desde la Segunda Guerra Mundial, un individuo de cada cinco -aproximadamente, 40 millones de personas- cambia anualmente de residencia en euA (Lipovetsky, 1990: 40). 
dictoria, según la cual los eslabones de la continuidad creativa se tornan cada vez más tenues y precarios, hasta el punto de que toda novedad supuestamente decisiva oculta, tras su exuberante aspecto, la cruda realidad del vacío:

La negación ha perdido su poder creativo. [...] Hemos entrado en [...] el posmodernismo, fase de declive de la creatividad artística cuyo único resorte es la explotación extremista de los principios modernistas. De ahí la contradicción de una cultura cuyo objetivo es generar sin cesar algo absolutamente distinto y que, al término del proceso, produce lo idéntico, el estereotipo, una monótona repetición (Lipovetsky, 1990: 82).

Se trata, como indica la famosa máxima publicitaria «nada se crea, todo se copia», de un aparente devenir, un recambio ramplón y banal de lo mismo, una «ficcionalización del mundo» (Sáez, 2007). La pregunta es: «¿Alguna vez se organizó, [...] se edificó, se acumuló tanto y, simultáneamente, se estuvo [...] tan atormentando por la pasión de la nada, de la tabla rasa, de la exterminación total?» (Lipovetsky, 1990: 34).

Desde una perspectiva semiopatológica, la transformación mediática de la comunicación social y la vida humana estriba, así entendida, en un exceso del flujo semiótico en relación con nuestra capacidad de asimilación: reclamos, mensajes, informaciones y, sobre todo, imágenes, pues el lenguaje visual sigue constituyendo, más allá de las últimas tendencias en el terreno del neuromarketing (García, 2015), la lingua franca de las nuevas generaciones videoelectrónicas. Si tras el universo cultural del hombre yace latente una historicidad fundamental, es porque toda imagen remite por principio, independientemente de su condición particular -visual, sonora, olfativa...-, a otras imágenes precedentes en cuanto referentes y soportes de memoria. La novedad del estado de cosas actual estriba, empero, en el potencial adquirido por las máquinas encargadas de la distribución de imágenes. Gracias al progreso experimentado por las técnicas reproductivas ${ }^{6}$ el furor de renovación total lleva hasta el extremo la lógica inmanente a la historia de la imagen, de manera que guardan tanta referencia entre ellas que terminan desencadenando una "perspectiva en abismo" (Peñuela, 1996), una miríada de insondables pedazos arqueológicos cuya

6 Durante los siglos xIx y xx, han sido difundidas tecnologías de reproducción técnica de la imagen que han transformado la infoesfera y, por ende, el imaginario. Debido a su excesivo precio, dichos medios han sido largo tiempo inaccesibles para gran parte de la población, lo cual otorgaba el poder sobre la producción semiótica a un círculo reducido de especialistas. No obstante, los años sesenta y setenta presenciaron la creación de unas condiciones adecuadas para la difusión masiva de los instrumentos técnicos de producción semiótica, cultura, arte e información (Berardi, 2007: 164 y ss.). 
multiplicación exponencial sobrepasa completamente la capacidad humana de interpretarlos (Baitello, 2004: 165).

En tal disposición de los términos, la idea de realizar una transmisión cultural con medios técnicos de comunicación constituye una de las mayores ilusiones de nuestra «sociedad de la información» pues, aunque comunicar sea condición necesaria para transmitir en lógica formal, no es condición suficiente. El espacio donde convivimos colectivamente no es un espacio vacío, ya que posee vinculaciones normativas previas, un consenso de mínimos proveniente de condicionantes educacionales, temperamentales y, en definitiva, eticistas, como son la religión, la familia o la escuela, pero también los influjos sociales, la publicidad o la moda, por citar algunos de los resortes motivacionales más pujantes durante los últimos tiempos. Pues bien, en la medida que pivota sobre la obsolescencia fulgurante y la aceleración disolvente, el exceso de comunicación predominante anula por principio la transmisión o «procesión»-del griego paradosis, traducido por «tradición»- de tales resortes, con menoscabo de los contenidos que conforman el corpus de la identidad personal, el modo de vida, la visión del mundo y la vida en común:

Vivimos [...] en lo que calificaría como un corte -o cesura- eticista: los códigos normativos heredados han entrado en crisis, pero no disponemos a nivel normativo de alternativas convincentes a nivel racional, y mucho menos a la altura de la virtualidad (Oliveira, 2010:244).

Desde esta perspectiva, resulta llamativo el contraste entre la facilidad de nuestra época para conquistar el espacio y su dificultad para dominar el tiempo. Y es que, mientras cruzar el espacio sólo requiere un artefacto, en el caso del tiempo es necesario un móvil más una máquina material o formal - como la escritura alfabética - y una institución social - por ejemplo, la escuela $-;^{7}$ sin embargo, ponemos toda nuestra libido en la nueva geografía de las redes, el parque tecnológico no cesa de seducirnos y las instituciones, en cambio, nos aburren profundamente, ya que tardan mucho más en renovarse que las industrias de la comunicación: «En otros términos, en un momento en que la Tierra entera puede seguir simultáneamente el Mundial de fútbol por la tele -sincronía-, Racine o La Pasión de Cristo se convierten en letra muerta para los escolares de Francia -diacronía-» (Debray, 2001: 20). Y si a pesar de todo, el sistema funciona y las

7 Ante la imposibilidad de hacerlo espontáneamente, la razón de ser de las instituciones sociales como la escuela estriba en transmitir de generación en generación el sistema de conocimientos compartidos -información, ideas, habilidades-, valores, creencias y normas de comportamiento que constituyen el modo de vida específico de una cultura con vistas a su ulterior desarrollo. 
instituciones se reproducen, lo hacen por inercia, sin adherencia ni sentido, cada vez más controladas por los «especialistas», esos «últimos curas» de los que hablaba Nietzsche, «hombres vencidos y sometidos de nuevo al dominio de la ciencia» (Nietzsche, 1972: 204). En definitiva, la obsolescencia acelerada de la nueva tecnología consolida cada vez más el abismo que separa los medios del archipiélago "comunicación» del continente "transmisión», o sea, el desequilibrio entre el aspecto material - «materia trabajada - e institucional - «organización materializada»- del dispositivo vehicular que transporta los bienes simbólicos, toda vez que la ampliación de las zonas de movilidad y el refuerzo de la conectividad técnica son directamente proporcionales al desfallecimiento de la conciencia histórica y del vínculo simbólico:

En la inversión del todo y de la parte, o incluso en la subordinación de lo duradero a lo efímero, podemos ver el indicio de una verdadera crisis de civilización, nombre oficial de las crisis de transmisión, de la que la actual desestabilización de los programas escolares debida a la influencia de los programas de la tele es a la vez síntoma y símbolo (Debray, 2001: 20).

\section{LA ORGANIZACIÓN DEL VACÍO EN LA VIDA DEL MERCADO}

Una vez bosquejada la «abstinencia» o «neutralización» normativa en el marco del nuevo mundo virtual, ${ }^{8}$ nos interesa evaluar la erosión que trae consigo en el ámbito de las pasiones humanas si queremos hacernos una idea cabal del conglomerado social contemporáneo pues, según la hipótesis que pretendemos demostrar, dicha erosión se constituye como el principal caldo de cultivo del acento individualista que lo caracteriza, para beneficio de la lógica acumulativa del capitalismo, tendencialmente insaciable, y con prejuicio de nuestra salud mental.

Desde luego, la crisis de transmisión también estriba en la formación cultural, toda vez que la banalidad de lo supuestamente visible ocupa tendenciosamente el noble asidero de la razón lógico-crítica hasta proscribir el pensamiento - en sentido enfático- por mor de un supuesto pragmatismo pseudoilustrado. Más que un mero cambio social, se trata de una verdadera mutación cognitiva de la humanidad, en virtud de la cual el número de palabras que usan habitualmente los jóvenes de formación media es de

8 Para indagar sobre esta problemática, crucial para nuestra investigación, desde una perspectiva más amplia, recomendamos la lectura de El problema de la conciencia bistórica (Gadamer, 2007) y La miseria del bistoricismo (Popper, 2006). 
650, en contraste con las 2.000 que utilizaban dos décadas atrás (Berardi, 2007: 191). No es casualidad, en tal disposición de los términos, la práctica desaparición de la autoridad y el prestigio del cuerpo docente, toda vez que el discurso del maestro viene asimilado a los mass media, mientras la apatía escolar, mezcla de atención dispersada y desenvuelto escepticismo ante el saber, neutraliza y momifica la enseñanza, pese a todos los esfuerzos dedicados a la innovación por parte de la investigación pedagógica (Lipovetsky, 1990: 39). A cambio, hemos desarrollado una capacidad inaudita para movernos velozmente en un horizonte hiperpoblado de estímulos visuales, así como competencias de elaboración semiconsciente altamente sofisticadas en la lectura de imágenes (Berardi, 2007: 191).

La profusión de bibliografía en este sentido contrasta, inexplicablemente, con la presencia testimonial de la dimensión afectiva en el discurso de los teóricos de los medios. Uno de los aspectos más reveladores de la actual crisis de transmisión es, sin duda, el poco tiempo que los padres dedican a sus hijos, en un mundo histórico donde el child-free se erige como denominador común y uno de cada cuatro niños occidentales es educado por solo uno de sus padres (Lipovetsky, 1990: 41), mientras el bombardeo semiótico por parte de los mass media alcanza niveles de intensidad y velocidad sin precedentes. La consecuencia más inquietante de ello redunda en el ámbito de la emoción. La transmisión del lenguaje y, por ende, el acceso a la sociabilidad siempre han estado mediados por la carnalidad, especialmente por el placer y la seguridad que proporciona la figura materna. ${ }^{9}$ Sin embargo, el contacto corporal y afectivo de la madre ha sido sustituido, lamentablemente, por la semiosis de la máquina, de tal suerte que la configuración emotiva de la generación videoelectrónica responde más a las máquinas televisivas y telemáticas que a su relación con la madre u otros seres humanos. De aquí se siguen implicaciones patológicas bien conocidas:

La emoción y la palabra tienden a escindirse en esa situación. El deseo crece en una esfera cada vez más separada de la verbalización y de la elaboración consciente y comunicable. Las emociones sin palabra alimentan la psicopatía y la violencia. No se comunica, no se dice, no se pone bajo una mirada compartida. Se agrede, se estalla. Las palabras sin emoción alimentan una sociabilidad cada vez más pobre, reducida a la lógica del dar y el tener (Berardi, 2007: 193).

9 La construcción ontogenética de los vínculos comunicativos y sociales hunde sus raíces en la amamantación y, posteriormente, pasa inevitablemente por el gesto de apropiación física del otro, en lo que constituiría una dinámica antropofágica si no fuera por la naturalidad que caracteriza a las operaciones vinculantes (Baitello, 2004: 163-164). 
En la medida que sitúa la «interconexión normativa» por debajo de las expectativas del individuo particular, la proyección de las nuevas tecnologías de la telecomunicación sobre la praxis histórico-vital también alcanza su eco siniestro en las entretelas de la urdimbre social, de tal suerte que nuestros deseos y prioridades pasan al primer plano. De hecho, cualquier persona atenta a lo que pasa debería reconocer fácilmente la pujante expansión de un malestar ciego y difuso, sin perfiles claros para la investigación. Pues bien, cuando el primer plano se convierte en el único se impone, paradójicamente, la difusión imparable del solipsismo, en lo que constituye uno de los síndromes más acuciantes de nuestra época.

Una forma más que recurrente de escapar al vacío concomitante a la actual crisis de contenidos es plegarnos a cierta fuerza externa que gobierna la existencia produciendo una ilusión de autonomía, enfermedad civilizatoria plenamente arraigada que desemboca en una autorrealización vicaria de la comunidad, dependiente de un poder anónimo y asimilado. Nos referimos al capitalismo avanzado, posindustrial e hiperconsumista, consagrado como sino de la civilización por la difusión vertiginosa de las nuevas tecnologías de la información, en el afán inaudito por extender su dominio del tiempo de producción al tiempo total de vida. ${ }^{10}$ Desde su colonización a distancia del «mundo de la vida», el modo de producción capitalista designa, efectivamente, la expresión sociopolítica por antonomasia donde la patología del vacío obtiene una fisionomía precisa, generando pautas y conductas con el alcance suficiente para constituir subjetividad colectiva. De aquí la tesis del posmodernismo como lógica cultural del capitalismo tardío (Jameson, 1991), toda vez que la fiebre del consumo contemporánea y su correspondiente «avidez de novedades» tan solo obedecen, en el afán compulsivo por amueblar la nada, a lo que los especialistas en mercadotecnia denominan «tendencias del mercado», esto es, las leyes del stablishment de la moda. ${ }^{11}$

10 Frente a la tesis de la «destrucción creadora» (Schumpeter, 1996), consideramos que el capitalismo constituye una especie de hidra o gorgona pues, como la lógica hegeliana, cada metamorfosis supera sus formas precedentes conservándolas; por eso, todavía persisten, junto al apogeo del paradigma inmaterial del trabajo, variantes contemporáneas de la «disciplina de fábrica» y la «cadena de montaje». En la década de los noventa, empero, el capitalismo rompe con la rígida distribución jerárquica de la empresa y se descentraliza, adaptándose a las nuevas condiciones de una sociedad reticular en su textura (Debord, 2003). Hemos intentado dilucidar en otro lugar la transformación del modo de producción capitalista, con el objeto de revisar la versión marxista de la enajenación a la luz de los procesos contemporáneos (García, 2015: 193-197).

11 Definida como «un impulso que hace de lo nuevo lo mejor en pos del placer de ver», la «avidez de novedades» se cifra en la mera «curiosidad», esto es, la forma espuria de la cura o, en términos de la analítica existencial del «ser ahí», «cuidado». Mientras que la curiositas implica -además de curiosidad- diligencia por saber, la «avidez de novedades» es meramente un cuidarse de lo más nuevo y 
No se trata, empero, de un proceso de apropiación de cosas propiamente dichas, sino de "un vínculo de apropiación heterodoxo, una alimentación que no posee la sustancia que requieren los cuerpos para estar alimentados y que genera todavía más déficits porque requiere reposición» (Baitello, 2004: 166). ${ }^{12}$ En este sentido, el capitalismo no solo se funda en el vacío sino que también lo promueve a gran escala, como revela el incremento ad infinitum de las cuotas de audiencia televisiva y, sistemáticamente, la compulsión patológica de consumir estímulos sin ninguna consideración histórica o prospectiva, a modo de material de fagocitación hiperactualista concebido por los ingenieros del marketing en función de valoraciones arbitrarias y unilaterales. ${ }^{13}$ Es la consagración definitiva de los «últimos hombres»-letzte Menschen- (Nietzsche, 1981: 39-40), la decadencia personificada en una suerte de «zombis eticistas» donde la sensibilización y la indiferencia hacia el mundo constituyen dos caras de una misma moneda: «Paradoja que se explica [...] por la plétora de informaciones que nos abruman y la rapidez con la que los acontecimientos massmediatizados se suceden, impidiendo cualquier emoción duradera» (Lipovetsky, 1990: 52).

No obstante, la desmovilización de las masas no implica delectación en la inadidad universal ni autodestrucción y, por así decirlo, el hombre cool responde más al espectador haciendo zapping que al decadente pesimista para quien todo es en vano. Y si todavía existen nómadas cuya desesperación refleja, alimentada por utopías y pasiones, el anhelo por emprender una línea de fuga hacia una tierra nueva, su desierto caliente participa, en el fondo, de la indiferencia contemporánea, en tanto que solo trae consigo, como atestigua mayo del 68, revoluciones castradas desde el principio, sin programa ni finalidad (Lipovetsky, 1990: 44-45). En efecto, la oposición del sin sentido pierde su radicalismo ante la frivolidad de la publicidad y del espectáculo, de manera que la lógica del «por qué no» se torna sistemática, y nuestras vidas transcurren en «secuencia-flash», sin patetismo ni abismo:

llamativo: "El "ser ahí” se deja arrastrar únicamente por el aspecto del mundo, una forma de ser en que se cura de quedar exento de sí mismo en cuanto "ser en el mundo", exento del ser cabe lo inmediata y cotidianamente "a la mano"» (Heidegger, 1989: 191).

12 Los medios generan déficits emocionales cubiertos por ellos mismos, en una relación de dependencia (Pross, 1983).

13 Lejos de representar una amenaza para el capitalismo, entendido como sistema experimental, sistemático y acelerado, basado en la combinación infinita de posibilidades, el vacío preponderante designa tanto su lógica fundamental como su realización extrema, en la medida que permite la aceleración de todas las experimentaciones sin encontrar apenas resistencia. 
Dios ha muerto, las grandes finalidades se apagan, pero a nadie le importa un bledo. [...] La indiferencia, pero no la angustia metafísica. [...] El relajamiento posmoderno liquida la desidia, el enmarcamiento o desbordamiento nihilista, la relajación elimina la fijación ascética. Desconectando los deseos de los dispositivos colectivos, movilizando las energías, temperando los entusiasmos e indagaciones relacionadas con lo social, el sistema invita al descanso, al descompromiso emocional (Lipovetsky, 1990: 36-37). ${ }^{14}$

En este contexto, la expansión triunfante del humorismo y la risa banal apenas esconde el inquietante florecimiento de las llamadas «enfermedades del vacío» (Sáez, 2011: 77-78). Si hasta hace poco tiempo la psiquiatría solo reconocía casos esporádicos de adicción al juego, la comida o el sexo, la transformación vertiginosa del capitalismo ha comportado formas de adicción a objetos sociales con implicaciones patológicas de dimensiones gigantescas, como la compra, el trabajo y, especialmente, las tecnoadicciones a la televisión, el teléfono móvil o internet. Como sabemos, la acumulación epidémica de la tecnoadicción y la depresión responden, más allá de las vicisitudes biológicas, neuroquímicas y psicológicas, a los mismos factores socioculturales, entre los cuales destaca la plétora de informaciones que nos circunda y su velocidad de rotación. Pues bien, además del vínculo psicosocial que coliga ambas patologías, la depresión constituye uno de los principales factores de riesgo para la adicción social y, a su vez, la enfermedad socioadictiva contribuye decisivamente al crecimiento exponencial de la morbilidad depresiva durante los últimos tiempos. ${ }^{15}$

Como observa Francisco Alonso, el síndrome adictivo social comprende varias secuencias: organización existencial dominada por el vínculo de subordinación al objeto, acto impulsional de la entrega al mismo, vivencia de recompensa, repetición del ciclo y acumulación de consecuencias nocivas (Alonso, 2003). En este contexto, la repetición del ciclo adictivo en escasos intervalos de tiempo constituye un factor de riesgo para la emergencia de episodios depresivos, en la medida que favorece el desempleo, el estrés económico y el desajuste familiar. Asimismo, el socioadicto dedica todos sus esfuerzos a la búsqueda del placer y, por ende, padece con frecuencia sentimiento de culpabilidad, vergüenza o desesperanza, esto es, los principales desencadenantes de la depresión. Por último, las adicciones

14 El hiperrealismo americano se revela, desde esta óptica, como el arte de nuestra época, por oposición a la angustia y la nostalgia del sentido en el existencialismo. La estética fría de la exterioridad y la distancia propia de las obras hiperrealistas no lleva ningún mensaje porque no hay nada que decir y, por tanto, se constituye como juego puro orientado al placer de la apariencia, sin inquietud ni denuncia; así pues, transforma el orden de la representación en un dispositivo maquinal y helado, con prejuicio de la dimensión humanista que define la historia del arte (Lipovetsky, 1990: 37-38).

15 De los 40 millones de cibersexoadictos en Occidente, España cuenta con más de 300.000, entre los cuales un 25\% sufre de trastorno depresivo (Alonso, 2011: 57-58). 
sociales implican factores neurobiológicos sumamente problemáticos, como la «hiposerotonergia» - parte del sustrato adictivo básico- o la «hipodopaminergia»-producida por la descarga masiva de dopamina en el momento de la recompensa, cuando el socioadicto experimenta el máximo placer-, cuya liberación excesiva genera un vacío especialmente proclive a la irrupción del trastorno depresivo.

\section{NARCISISMO COLECTIVO}

Vistas así las cosas, podríamos decir que, como revela la etiología de los términos «consumir» $\mathrm{y}$ «consumo» - «devorar, agotar, destruir» $\mathrm{y}$ «morir, acabar, sucumbir»-, la devoración de estímulos - sentido activo- generada por la ausencia de consenso en el dominio de los contenidos a nivel normativo designa un fenómeno ambivalente, en la medida que también presupone ser devorado por ellos - sentido pasivo-. Ahora bien, la iconofagia/antropofagia desarrollada en el universo cultural de la comunicación tiene implicaciones que rebasan la perspectiva individual donde se funda la tradición psicopatológica, en la medida que la «recodificación» del ser humano como bomo zombicus en la vida del mercado trae consigo un modo de socialización sin precedentes, una nueva fase en la historia del individualismo occidental que termina con el ideal moderno de subordinar la indeterminación constructiva del individuo a sistemas de organización uniformes y normas racionales colectivas, desde la voluntad general hasta el partido revolucionario, pasando por las convenciones sociales o el imperativo moral. Si bien es cierto que la cultura occidental ha pivotado invariablemente, al menos desde el siglo xvII, sobre el principio de libertad individual, la vigente crisis de transmisión desplaza la ideología individualista desde las formas político-económicas de control tradicionales hasta la vida cotidiana, promoviendo indiscriminadamente valores como la singularidad subjetiva y la realización personal:

Vivir libremente sin represiones, escoger íntegramente el modo de existencia de cada uno: he aquí el hecho social y cultural más significativo de nuestro tiempo, la aspiración y el derecho más legítimos a los ojos de nuestros contemporáneos. [...] Neofeminismo, liberación de costumbres y sexualidades, reivindicaciones de las minorías religiosas y lingüísticas, tecnologías psicológicas, deseo de expresión y de expansión del yo, movimientos "alternativos», por todas partes asistimos a la búsqueda de la propia identidad, y no ya de la universalidad que motiva las acciones sociales e individuales (Lipovetsky, 1990: 8). 
Así pues, los nuevos movimientos de liberación individual promueven un nuevo prototipo social caracterizado por una concepción absolutizada y aséptica de la libertad, entendida como simple libertad de elección ante la oferta ilimitada que la revolución permanente del mercado hace posible, a costa del concepto ontológico-existencial de libertad como responsabilidad de «hacer-por-ser» en la existencia, basada en una estructura normativa fuerte y vinculante - por ejemplo, los viejos conceptos de «verdad moral» $\mathrm{O}$ «vida buena» $-{ }^{16}$ Privado de todo apoyo trascendente para cruzar el desierto, el mono-individuo contemporáneo no solo se vanagloria, elevado como único árbitro de dilucidación moral, de su presunta liberalización del riesgo que implica subordinar los juicios de valor a autoridades invisibles a la luz de la razón individual, sino que convierte el individualismo solipsista y zómbico, más allá de la necesidad de ocuparnos de nosotros mismos para sobrevivir, en una especie de ideología militante capaz de afirmar normativamente la bondad intrínseca de la opción que Carlos Oliveira denomina «hiperindividualista», en la medida que todos los gustos y comportamientos pueden convivir, convertidos en «flotantes» como las fluctuaciones de la opinión pública, sin excluirse mutuamente (Oliveira, 2010: 239-240).

Sin embargo, la falta de sensibilidad moral característica de semejante «estructural sobre-yo-idad» pone de manifiesto, desde el punto de vista del bíos aristotélico - la "vida buena», cualificada sociopolíticamente-, una regresión moral-eticista a nivel civilizatorio que amenaza con transformar la sociedad en un desierto paradójico. Lamentablemente, mientras los principios intangibles y absolutos tradicionales -iglesia, ejército, trabajo, partidos políticos, etc.- se truecan en organismos exangües donde nadie invierte nada, el hiperindividualismo monodologista está arruinando progresivamente los fundamentos antropológicos de la sociedad, nuestra condición comunitaria y el mismo concepto de universalidad humana, en beneficio de una liberación del espacio privado que fagocita todo en su interior, incluidos los valores trascendentales. La moralidad autoclave trae consigo, en suma, el repliegue autárquico del individuo, ilustrado por la

16 Desde la óptica del «nihilismo propio», el ser es fondo y abismo, ya que toda fundamentación tendría que deponerlo hasta convertirlo en ente (Heidegger, 1991: 175-176). De aquí se sigue la posibilidad de «autotrascendernos» constantemente que tenemos, en cuanto seres «abiertos» e «indeterminados», en pos de nuestra vocación de ser, haciendo estallar toda imagen fija. Ahora bien, la capacidad creadora de plasticidad propia donde se cifra la libertad constituye, asimismo, una «responsabilidad de sí1». En su condición de lanzado a un poder-ser, el «ser ahí» es constitutivamente forastero, es decir, no posee una «naturaleza» dada anterior a su actualización existencial. Pues bien, esta condición precaria -sin esencia ideal- de la identidad humana conlleva el deber constitutivo de hacerse a uno mismo, en un mundo que nos ofrece la posibilidad de existir y, al mismo tiempo, grandes dificultades para ello. 
disposición compulsiva al consumo, pero también por la moda del psicoanálisis y de los «psi», erigidos como nuevos predicadores del desierto.

No nos pasa desapercibido que, así entendido, el avance del desierto contradice aparentemente el devenir virtual del mundo. Como sugerimos al principio, las tecnologías de la telecomunicación consuman simultáneamente la desterritorialización y la localización del individuo, en tanto que nos arrojan al espacio virtual de la red. En este contexto, las comunicaciones inalámbricas reconfiguran las coordenadas geográficas tradicionales de forma que nuestros movimientos se cifran inevitablemente en los parámetros de los nodos. Nos encontramos, por tanto, atrapados en la red, hasta el prurito que no podemos evadirnos de ella: si desconectamos el dispositivo en cuestión, no estamos accesibles pero sí localizables, pues la desconexión también tiene referencia espacial; si ocultamos el número en una llamada, nuestra posición es igualmente determinable cuando entablamos la conversación; sólo lograríamos desengancharnos rechazando las nuevas tecnologías como obra del diablo, pero casi nadie está dispuesto a sufrir las consecuencias que tendría en un mundo virtual. ${ }^{17}$

Vistas las cosas así, la disponibilidad absoluta tiene como correlato lo que el marketing acostumbra a vendernos con el célebre eslogan: «La telecomunicación acerca a las personas». No se trata, evidentemente, de la sensación de contigüidad espacial que experimentamos cuando contactamos con alguien lejano mediante las telecomunicaciones, olvidando la distancia que efectivamente nos separa. Dado que determina su ubicuidad permanente, global y perfecta, los habitantes de la infoesfera se encuentran, en un sentido virtual, potencialmente siempre «en contacto» con los demás: «Se ha convertido en una célula - mónada- unida a las demás células -nómadas-» (Lynch, 2010: 85). En efecto, el capitalismo ha conseguido la hazaña de situar nuestra «insociable sociabilidad» (Kant, 1978) en un horizonte de relativo equilibrio donde los conflictos sociales son atajados sin mayores dificultades por los mecanismos del mercado y el sistema massmediático organizado como monopolio de la comunicación.

Una de las mejores descripciones de nuestra sociedad se cifra, sorprendentemente, en la Monadología -1704- (Lynch, 2010: 95-98). Según Leibniz, el mundo se compone de «mónadas», unidades elementales e indivisi-

17 Enrique Lynch no puede mostrarse más sugestivo al respecto: «El teléfono celular o móvil parece el chisme orwelliano por antonomasia, el artilugio que nos mete en el sistema de la vigilancia total imaginado por Bentham, aquel panóptico que reelaboró con vocación crítica Michel Foucault en Surveiller et punir» (Lynch, 2010:85-86). No es difícil imaginar tras semejante diseño un proyecto de dominación basado en el control de las conciencias, en detrimento de todos los esfuerzos encaminados a la consumación de una democracia del tiempo real, la inmediatez y la ubicuidad. 
bles que poseen una naturaleza primaria y tres atributos fundamentales, a saber, igualdad, autismo y armonía: aunque están aisladas, las mónadas son solidarias entre sí. Pues bien, aunque el progreso científico ha demostrado que el universo no es monádico sino cuántico, el apogeo del individualismo revela que la condición social sí lo es: somos mónadas autónomas conectadas en un conglomerado virtual que sostiene nuestra compenetración recíproca. Más allá del modelo leibniziano, la «muerte de Dios» ha favorecido, empero, la erección de un «nuevo ídolo» donde cifrar el equilibrio social:

La técnica [...] es nuestro Dios ausente, circunstancia que hace toda resistencia a ella no solo inútil sino absurda, pues $[\ldots]$ nos suministra $[\ldots]$ una nueva topografía de la vida pasa$\mathrm{da}$, presente y futura; nos asigna nuestra coordenada existencial, nuestro verdadero lugar en el mundo, que es el lugar que ocupamos para los demás (Lynch, 2010:97).

Desde esta perspectiva, existe la opinión cada vez más extendida de que la realidad virtual no es un simple medio de información, sino que proporciona todo un espacio social por medio de las redes telemáticas, entendidas como interfaces de comunicación para encontrar al otro mediante múltiples captores y efectuadores donde cada participante está representado por un «clon», lo cual permite - en teoría- una interactividad total e, incluso, la posibilidad de adoptar el punto de vista de los interlocutores (Quéau, 1995: 69).

El desarrollo vertiginoso de las tecnologías P-M-P y del lenguaje informático VRML - Virtual Reality Modelling Language-, inventado por Marc Pesce en 1994, ofrece la posibilidad, mediante la distribución de escenas tridimensionales en el Web Space, no solo de que varias personas interactúen en el mismo entorno infovirtual, sino de intervenir en distintos escenarios virtuales simultáneamente, más allá de otros espacios telemáticos aptos para la intercomunicación en tiempo real de textos y conversaciones habladas pero no para la interacción, como los escenarios unidimensionales -basados en interrelaciones textuales- de los Muds -Multiusers Dimensions, Multiusers Dungeons, Multiusers Dialogues- y los chats, o los lugares virtuales bidimensionales, donde las imágenes carecen de profundidad, en detrimento de la libertad de expresión y acción.

Las tecnologías P-M-P son capaces de simular cualquier espacio de interrelación característico de la vieja realidad espacio-temporal, así como construir nuevos escenarios donde todo usuario puede crear su propio avatar, imprimirle múltiples identidades específicas en una suerte de inmersión representativa - el sujeto deviene multipersonal- y salir volunta- 
riamente al proscenio electrónico a fin de interrelacionarse con otras máscaras digitales, manteniendo reuniones virtuales de todo tipo. ${ }^{18}$ Como la televisión digital por cable, los escenarios virtuales pueden ser abiertos - plazas- o cerrados - clubes-; son válidos para desarrollar actividades productivas en empresas, tiendas o universidades, pero también para mantener relaciones íntimas y divertirse. La diferencia estriba en que todos pueden intervenir activamente en ellos, experimentando las consecuencias de las acciones ajenas (Echeverría, 2000: 88-121). ${ }^{19}$

En este contexto, los nuevos movimientos sociales han depositado gran parte de sus esperanzas en las infinitas posibilidades de interconexión permitidas por el progreso tecnológico, capaces de construir intersubjetividad en la distancia, y fenómenos como la cultura backer de los 90, el cyberfeminismo, el 15-M, la Primavera Árabe u Occupy Wall Street han generado la opinión pública de que las redes sociales permiten cambiar los equilibrios del poder fáctico reticularmente, desde el anonimato y la difusión, como parte de una estrategia de liberación ciudadana, articulada por una noción de subjetividad como devenir «manada» o «multitud» (Hardt y Negri, 2004).

Con todo, la realidad desmiente cruelmente las expectativas creadas alrededor de lo virtual como entorno privilegiado, multicultural y plurilingüístico para la interrelación personal, con la ventaja de agrupar personas distantes geográficamente. Si el lenguaje se define como «genio de la especie», es porque juega un papel crucial para la constitución de la sociedad (Nietzsche, 1992: 354). Pues bien, para desgracia del filósofo intempestivo, la virtualización del intercambio lingüístico en detrimento de su dimensión corporal transforma la llamada «ontología de la distancia» de tal manera que, cuando dos interlocutores virtuales intercambian, como suele ser habitual, detalles triviales sobre sus vidas privadas en el espacio público, adaptan inconscientemente su registro ontológico de interacción con el «mundo» a la nueva realidad de segundo grado, de modo que los habitantes del viejo espacio espacio-temporal no existen en un sentido «trascendental» sino meramente empírico, su presencia pasa completamente desapercibida e, incluso, puede resultar embarazosa, ya que deben ser desalojados velozmente de su materialidad en cuanto información o virtualidad; como consecuencia:

18 Para indagar la cuestión de los avatares, nos remitimos a la obra de Bruce Damer (1998).

19 Michael Powers (1997) ha analizado con el debido rigor la historia de los lugares virtuales, así como los procedimientos para crearlos. 
Acabamos por amar lo lejano y por odiar lo cercano porque este último está presente, porque huele, porque hace ruido, porque molesta, a diferencia de lo lejano que se puede hacer desaparecer con el zapping... Estar más cerca de quien está lejos que de quien está a nuestro lado es un fenómeno de disolución política de la especie humana. La pérdida del propio cuerpo comporta la pérdida del cuerpo de los demás, en beneficio de una especie de espectralidad de lo lejano (Virilio y Petit, 1996: 42-46).

No obstante, los interlocutores virtuales tampoco existen sensu stricto pues, en el íntimo "parloteo» por razón del cual nos desentendemos de todo aquello que sucede en el reino del primer orden, constituyen a menudo una mera excusa antropológica como método para comprobar nuestra existencia, en un sentido cartesiano. De tal suerte que, lejos de consagrar "comunidades virtuales», entendidas como "grupos sociales que surgen en la red cuando un número suficiente de gente desarrolla en ella discusiones públicas $[\ldots]$ con tanta carga de sentimientos como para formar redes de relaciones personales en el ciberespacio» (Rheingold, 1994: 5), los nuevos espacios virtuales no hacen sino reforzar la lógica de la indiferencia como grado suplementario de la ascensión imparable del individuo dedicado al self-service narcisista.Y es que, cuando "contactamos» con los otros bajo su égida, lo único que reforzamos es el principio originario que define nuestra condición monádica, mientras «el no otro -el "in-otro" - es una proyección de mi deseo de "interlocutabilidad" y, por tanto, el grado "xerox" -Baudrillard- de la alteridad» (Oliveira, 2010: 237).

\section{CONCLUSIÓN}

En resumen, el gestarse de la comunidad ha sido conquistado por un poder subrepticio que escapa a la voluntad humana, toda vez reducida a mero espacio de transmisión y reverberación sin coordenadas mayores, referencias estables y certezas absolutas. No es un fenómeno aislado, ni tampoco su acumulación cuantitativa, sino una patología de civilización que, si bien posee expresiones mórbidas en cada biografía individual, está devastando progresivamente el espacio abierto de lo común en nombre de la ingravidez indiferente y la "anemia emocional», definida clínicamente como «la deficiencia en el reconocimiento y aceptación del afecto, la aceptación y la cercanía de los otros» (Horvitz, 1982). A pesar de tener un alcance cada vez más universal, el proceso de "personalización» o «atomización» que designa el «zombismo normativo» no afecta con la misma intensidad, evidentemente, a todas las zonas del planeta. Por otro lado, sería absurdo 
reducir el conjunto social a un solo principio homogéneo, dado que nuestras sociedades utilizan numerosos criterios específicos en su funcionamiento interno. Sin embargo, estamos en condiciones de asegurar, llegados a este punto, que las transformaciones vertiginosas de nuestro presente, la metamorfosis del capitalismo, el desarrollismo tecnológico y la consolidación del sistema global de comunicación comportan, desde una perspectiva comparativa e histórica, una mutación sociológica con una «significación imaginaria central»-Castoriadis. ${ }^{20}$

Se trata, por así decirlo, del desvanecimiento del ethos donde otrora reposaba la praxis colectiva en perjuicio de su densidad ontológica, esto es, el horizonte de sentido sin causa ni telos que vincula, por mor de su capacidad para afectar y ser afectadas, la miríada de fuerzas intensivas que entretejen el «mundo de la vida». De tal suerte que las operaciones sociales se tornan exógenas, en virtud de órdenes anónimas pero con el alcance suficiente para juntar soledades difuminando sus diferencias allí donde no hay más que un desierto apático, ese «mundo sin territorio»o «lugar sin límites» por donde deambulan conectadas a distancia, con menoscabo de toda relación motivada por el puro placer de conocerse. Por eso, «cuando nos experimentamos "ocupados" y "no disponibles" no es porque la variedad de nuestras relaciones con los otros o con el trabajo sean excesivas sino porque, en realidad, carecemos de relación» (Sáez, 2011: 87). Tras el abandono de los valores y las instituciones, es la propia intersubjetividad la que desfallece, en un desierto asfixiante de autonomía y neutralidad donde la soledad en sentido noble, como aquella que caracterizaba a los espíritus excepcionales en la noche de los tiempos, se ha convertido en un hecho banal e indiferente, sin tragedia:

La libertad, como la guerra, ha propagado el desierto, la extrañeza absoluta ante el otro. «Déjame sola», deseo y dolor de estar solo. Así llegamos al final del desierto; previamente atomizado y separado, cada uno se hace agente activo del desierto, lo extiende y lo surca, incapaz de «vivir» el Otro (Lipovetsky, 1990: 48).

20 Las significaciones centrales son articulaciones de sentido últimas, en cuanto tramas que sostienen el significado de la identidad y la percepción de su lugar en el mundo. Por ejemplo, en el Medievo, la significación imaginaria central era Dios, sin la cual carecían de sentido todas las significaciones vinculadas con los rituales religiosos, las vestimentas o los números. En nuestro caso, Castoriadis asimila la significación originaria central a la expansión del dominio racional del mundo, en virtud del cual tenemos el concepto de educación para formar «buenos ciudadanos», la seguridad epistemológica de la ciencia o la confianza en la técnica de cara a alargar la vida (Cristiano, 2009: 29-30). 


\section{BIBLIOGRAFÍA}

Alonso F. (2011): "Factores determinantes en el incremento del trastorno depresivo en los últimos setenta años», en SáEz, L. y otros (eds.) (2011): Occidente enfermo, Múnich, Grin.

- (2003): Las nuevas adicciones, Madrid, Tea.

Battello, N. (2004): «Las cuatro devoraciones. Iconofagia y Antropofagia en la comunicación y en la cultura», Comunicación. Revista Internacional de Comunicación Audiovisual, Publicidad y Estudios Culturales, 2, pp. $159-168$.

Beradi, F. (2007): Generación post-alfa, Buenos Aires, Tinta Limón.

Cristiano, J. (2009): Lo social como institución imaginaria, Eduvim, Villa María.

DAmer, B. (1998): Avatars!, Berkeley, Peachpet.

Debord, G. (2003): La sociedad del espectáculo, Valencia, Pre-textos.

DEBRAY, R. (2001): Introducción a la mediología, Barcelona, Paidós.

ECHEVERría, J. (1999): Los señores del aire, Barcelona, Destino.

- (2000): Un mundo virtual, Barcelona, Plaza \& Janés.

Eco, U. (1995): Apocalípticos e integrados, Barcelona, Tusquets.

Foucault, M. (2012): Vigilar y castigar, Madrid, Biblioteca Nueva.

GADAMER, H. G. (2007): El problema de la conciencia bistórica, Madrid,Tecnos.

GARCíA, B. (2015): «De las máquinas totalitarias al "Capitalismo emocional". Consideraciones en torno a la impostura de la "deshinibición" ", Ágra: papeles de Filosofía, 34(1), pp. 189-211.

Hardt, M. y Negri, T. (2004): Multitud, Barcelona, Debate.

HeIdegger, M. (1991): La proposición del fundamento, Barcelona, Serbal.

- (1989): Ser y Tiempo, Madrid, FCE.

Horvitz, A. (1982): "Anemia emocional», Brain/Mind Bulletin, 7(13), pp. 1-4. Jameson, F. (1991): El posmodernismo o la lógica cultural del capitalismo avanzado, Barcelona, Paidós.

KANT, I. (1978): Filosofía de la bistoria, Méjico, FCE.

LÉvy, P. (1999): ¿Qué es lo virtual?, Barcelona, Paidós.

Lipovetsky, G. (1990): La era del vacío, Barcelona, Anagrama.

LynCH, E. (2010): «La felicidad de las mónadas», en Aranzueque, G. (ed.) (2010): Ontología de la distancia, Madrid, Abada.

Nietzsche, F. (1992): La gaya ciencia, Caracas, Monte Ávila.

- (1972): Más allá del bien y del mal, Madrid, Alianza.

- (1981): Así babló Zaratustra, Madrid, Alianza. 
Oliveira, C. (2010): "Acerca de las aporías del hiperindividualismo contemporáneo», en Aranzueque, G. (ed.) (2010): Ontología de la distancia, Madrid, Abada.

Ortega y Gasset, J. (2005): Meditaciones del Quijote, Madrid, Cátedra.

Peñuela, E. (1996): Urdidura de sigilos, São Paulo, Annablume/ECAusP.

Popper, K. (2006): La miseria del historicismo, Madrid, Alianza.

Powers, M. (1997): How to Program Virtual Communities, Nueva York, ZiffDavis.

Pross, H. (1983): La violencia de los símbolos sociales, Barcelona, Anthropos.

QuÉAu, P. (1995): «Le virtuel: un état du réel», en Lliopoulos, J. y CoHEN-TANnOudJI, G. (eds.): Virtualité et réalité dans les Sciences, París, Frontières.

Rheingold, H. (1994): The virtual community, Harper, Reading.

SÁEz, L. (2011): «Enfermedades de Occidente. Enfermedades actuales del vacío desde el nexo entre filosofía y psicopatología», en SÁEz, L. y otros (eds.) (2011): Occidente enfermo, Múnich, Grin.

- (2007): «Ficcionalización del mundo. Aportaciones para una crítica de patologías sociales», Revista de Filosofía Universidad de Costa Rica, 45(115-116), pp. 57-69.

SCHumpeter, P. (1996): Capitalismo, socialismo y democracia, Madrid, Folio.

Virilio, P. y Petit, P. (1996): La politique du pire, París, Textuel.

Wittgenstein, L. (1988): Sobre la certeza, Barcelona, Gedisa. 